\title{
Involvement of dopamine loss in extrastriatal basal ganglia nuclei in the pathophysiology of Parkinson's disease
}

\author{
Abdelhamid Benazzouz 1,2 *, Omar Mamad ${ }^{1,2,3}$, Pamphyle Abedi 1,2,3, Rabia Bouali-Benazzouz ${ }^{4}$ and \\ Jonathan Chetrit ${ }^{1,2}$ \\ 1 Institut des Maladies Neurodégénératives, Université Bordeaux Segalen, UMR 5293, Bordeaux, France \\ ${ }^{2}$ CNRS, Institut des Maladies Neurodégénératives, Université Bordeaux Segalen, UMR 5293, Bordeaux, France \\ ${ }^{3}$ Faculté des Sciences, Equipe Rythmes Biologiques, Neurosciences et Environnement, Université Mohamed V-Agdal, Rabat, Morocco \\ ${ }^{4}$ Institut Interdisciplinaire des Neurosciences, Université Bordeaux Segalen, UMR 5297, Bordeaux, France
}

\section{Edited by:}

Isidro Ferrer, University of

Barcelona, Spain

Reviewed by:

Nicola Pavese, Imperial College London, UK

Concepcio Marin, Institut $d^{\prime}$ 'nvestigacions Biomèdiques

August Pi i Sunyer, Spain

${ }^{*}$ Correspondence:

Abdelhamid Benazzouz, Institut des Maladies Neurodégénératives and CNRS, Université Bordeaux Segalen, UMR 5293, 146 Rue Léo-Saignat, 33076 Bordeaux Cedex, France

e-mail: abdelhamid.benazzouz@ubordeaux2.fr
Parkinson's disease (PD) is a neurological disorder characterized by the manifestation of motor symptoms, such as akinesia, muscle rigidity and tremor at rest. These symptoms are classically attributed to the degeneration of dopamine neurons in the pars compacta of substantia nigra (SNc), which results in a marked dopamine depletion in the striatum. It is well established that dopamine neurons in the SNc innervate not only the striatum, which is the main target, but also other basal ganglia nuclei including the two segments of globus pallidus and the subthalamic nucleus (STN). The role of dopamine and its depletion in the striatum is well known, however, the role of dopamine depletion in the pallidal complex and the STN in the genesis of their abnormal neuronal activity and in parkinsonian motor deficits is still not clearly determined. Based on recent experimental data from animal models of Parkinson's disease in rodents and non-human primates and also from parkinsonian patients, this review summarizes current knowledge on the role of dopamine in the modulation of basal ganglia neuronal activity and also the role of dopamine depletion in these nuclei in the pathophysiology of Parkinson's disease.

Keywords: dopamine, extrastriatal dopamine, basal ganglia, globus pallidus, subthalamic nucleus, Parkinson's disease

\section{INTRODUCTION}

Parkinson's disease (PD) is a neurological disorder characterized by the manifestation of motor symptoms such as akinesia, muscle rigidity and tremor at rest. These motor deficits are classically attributed to the degeneration of dopamine neurons in the pars compacta of substantia nigra $(\mathrm{SNc})$, which result in a marked dopamine depletion in the striatum, the primary projection region of the SNc. Furthermore, it is well established now that dopamine neurons in the SNc innervate not only the striatum but also other basal ganglia nuclei including the two segments of globus pallidus, the external part (GPe in primate, the equivalent of GP in rodents) and the internal part (GPi in primate, the equivalent of entopeduncular nucleus in rodents), as well as the subthalamic nucleus (STN; Smith and Villalba, 2008). Dopamine has been shown to modulate the neuronal electrical activity of all these basal ganglia nuclei (Rommelfanger and Wichmann, 2010).

Dopamine cell degeneration in the pathophysiology of $\mathrm{PD}$ is considered as the main hallmark of the disease (Agid and Blin, 1987; Hornykiewicz, 1998). Indeed, dopamine depletion by stereotaxic injection of 6-hydroxydopamine (6-OHDA) in the rat or by systemic injections of 1-methyl-4-phenyl-1,2,3,6tetrahydropyridine (MPTP) in the non-human primate resulted in alterations of the firing rate and/or patterns of GPe, GPi and STN neurons. The tonic regular pattern in the normal condition changed toward a pathological exaggerated burst firing with oscillations after dopamine cell lesions in the substantia nigra ( $\mathrm{SNc}$; Albin et al., 1989; DeLong, 1990; Bergman et al., 1994; Wichmann et al., 1994; Boraud et al., 1998; Ni et al., 2000, 2001b; Magill et al., 2001; Breit et al., 2007; Rivlin-Etzion et al., 2010). Similar bursty pattern has been reported in PD patients when microrecordings have been done during surgery for the implantation of deep brain stimulation electrodes (Hutchison et al., 1998; Benazzouz et al., 2002). According to the classical model of the anatomofunctional organization of the basal ganglia, the pathological activity recorded in basal ganglia nuclei has been identified as a consequence of dopamine depletion in the striatum (Albin et al., 1989).

In normal physiological conditions, dopamine has long been known to be a crucial neuromodulator of striatal processing of cortical informations carried by glutamatergic synapses on medium spiny neurons, which represents the principal projection neurons of the striatum. Dopamine excites medium spiny neurons of the "direct" pathway through dopamine D1 receptors, while it inhibits striatal neurons of the "indirect" pathway through dopamine D2 receptors (Alexander and Crutcher, 1990; Surmeier et al., 2007). In the context of PD, studies of the neuronal activity in the basal ganglia of MPTP monkeys and 6-OHDA rat models of the disease suggested that the direct and the indirect pathways are differentially affected by the loss of dopamine in the striatum. 
The GABAergic inhibitory direct striato-GPi pathway becomes underactive, whereas the GABAergic projection from the striatum to the GPe of the indirect pathway becomes overactive, leading to the reduced activity along the inhibitory GPe-GPi and GPeSTN pathways. Thus, it is suggested that exaggerated oscillatory bursts in STN and in GPi may have been secondary to tonic disinhibition of both structures from GPe after loss of dopamine in the striatum. However, the role of dopamine depletion in these extrastraiatal basal ganglia nuclei in the pathophysiology of PD is still not clearly defined. Nevertheless, in view of the demonstrated physiologic actions of dopamine on pallidal and STN neuronal activity as well as the effects on motor behavior of local injection of dopamine drugs, it is assumed that the loss of pallidal and subthalamic dopaminergic control would contribute to the motor symptoms in PD (Rommelfanger and Wichmann, 2010; Wilson and Bevan, 2011).

The pallidal complex and the STN are innervated by nigral dopamine fibers, by separate fiber system and also by collaterals of nigrostriatal fibers. This has been shown in rodents (Lindvall and Bjorklund, 1979; Debeir et al., 2005; Anaya-Martinez et al., 2006), in non-human primate (Nobin and Bjorklund, 1973; Parent and Smith, 1987; Lavoie et al., 1989; Parent et al., 1989; François et al., 1999; Hedreen, 1999; Jan et al., 2000) and in human brains (Nobin and Bjorklund, 1973; Cossette et al., 1999; François et al., 1999; Jan et al., 2000). Dopamine acts via five receptor subtypes subdivided into two receptor families: D1 (D1 and D5 subtypes) and D2 (D2, D3 and D4 subtypes). All are prototypic of G-protein-coupled receptors with dopamine D1 receptors being positively linked to adenylate cyclase and D2 receptors had negative coupling to the enzyme (Kebabian and Calne, 1979). A large number of experimental studies reported that functional dopamine receptors are expressed in the striatum and also in the GPe, GPi and STN and that dopamine modulates their neuronal activity through a variety of mechanisms via preand post-synaptic sites (Smith and Villalba, 2008; Rommelfanger and Wichmann, 2010).

Dopamine, through D1 and D2 family receptors, in the pallidal complex and the STN may modulate the motor circuit and consequently dopamine depletion in these structures may play a role in the pathophysiology of PD. Lesions of dopamine neurons in the SNc in rodents and monkeys have been shown to reduce dopamine levels in GPe, GPi and STN in addition to the striatum (Parent et al., 1990; François et al., 1999; Jan et al., 2000; Fuchs and Hauber, 2004).

\section{DOPAMINE DEPLETION IN THE GLOBUS PALLIDUS}

Rajput et al. (2008) have recently reported a marked loss of dopamine in the GPe $(-82 \%)$ of PD patients with a severe loss of dopamine in the caudate $(-89 \%)$ and the putamen $(-98.4 \%)$. Based on the conclusions of a previous experimental study (Pifl et al., 1991), the authors suggested that pallidal dopamine participates in the functional compensation against the severe loss of dopamine in the striatum at the early stage of the disease. It has been shown that in the MPTP-treated primate model of parkinsonism in which the animals with stable parkinsonian symptoms showed a marked pallidal dopamine depletion, asymptomatic animals showed normal pallidal dopamine levels but had very marked striatal dopamine deficit (Pifl et al., 1991). Similarly, imaging studies using positron emission tomography in $\mathrm{PD}$ patients reported that while patients with severe advanced stage of the disease had significantly reduced $18 \mathrm{~F}$-dopa uptake in the striatum, GPe and GPi, patients at mild stage of the disease demonstrated a severely reduced $18 \mathrm{~F}$-dopa uptake in the striatum but normal uptake in GPe and GPi (Whone et al., 2003; Pavese et al., 2011). Furthermore, an increase in 18F-dopa uptake in GPi has been reported in early stage PD (Rakshi et al., 1999; Whone et al., 2003; Moore et al., 2008; Pavese et al., 2011). Together, these studies postulate that dopamine plays a key role in the compensatory up-regulation of the nigro-pallidal dopamine projection in the early stages of PD representing a compensatory adaptive mechanism to preserve functionality. In contrary, dopamine depletion in the two pallidal segments (GPe and GPi) may participate in the aggravation of motor symptoms in the late stages of PD.

Studies on the expression of dopamine receptors in the pallidal complex of parkinsonian brains reported conflicting data. While some studies found no difference in dopamine D1R expression in the GPe and GPi (Rinne et al., 1985; Cortés et al., 1989), others found dopamine D1R expression unchanged in the GPi and decreased in GPe (Hurley et al., 2001). Dopamine D2 receptors, including D3 receptors, were unchanged in both GPe and GPi (Bokobza et al., 1984; Cortés et al., 1989; Ryoo et al., 1998). The absence of changes in the expression of D1 and D2 receptors can be explained by the fact that patients were under dopaminergic medication before death and that the treatment is likely to normalize the expression of these receptors. This may be true for the striatum but not for the pallidal complex as in MPTP monkeys, the expression of dopamine D3 receptors was reduced in the caudate nucleus but not in the GPe and GPi and that L-Dopa treatment normalized the hypoexpression of dopamine D3 receptors in the caudate nucleus and increased to a level higher than normal in GPi without any change in the GPe (Bézard et al., 2003).

The contribution of pallidal dopamine in the pathophysiology of PD has also been demonstrated in rodents. Activation of D1 or D2 dopamine receptors in the GP induced movement facilitation (Sañudo-Peña and Walker, 1998). In contrast, local blockade of D1 and/or D2 receptors by intra-pallidal infusions of specific antagonists induced akinesia in rats (Hauber et al., 1998; Hauber and Lutz, 1999). Similarly, in rats bearing a unilateral 6-OHDA lesion, it has been shown that blockade of either dopamine D1 or D2 receptors reduced apormorphine-induced turnings and that dopamine infusion into the GP improved motor deficits in the same animal model (Galvan et al., 2001). Furthermore, we have recently shown that intra-pallidal injection of 6-OHDA produced deficits of dopaminergic transmission that caused asymmetrical motor impairment and reduction of locomotor activity in the rat (Bouali-Benazzouz et al., 2009; Abedi et al., 2013). Together, these studies provide arguments that dopamine transmission within the globus pallidus is necessary to achieve motor control and that its lack plays a role in the pathophysiology of parkinsonian motor symptoms, in addition to dopamine depletion in the striatum. 


\section{DOPAMINE DEPLETION IN THE SUBTHALAMIC NUCLEUS}

STN holds a pivotal position in basal ganglia circuitry exerting an excitatory drive on the output structures of the system (Albin et al., 1989; Alexander and Crutcher, 1990). The STN has been shown to play a key role in motor control, as its hyperactivity with oscillatory bursts has been associated to parkinsonian motor deficits. The motor symptoms can be reversed by selective STN lesion or high frequency stimulation (Bergman et al., 1990; Benazzouz et al., 1993; Limousin et al., 1995; Krack et al., 2003). Several studies have suggested the implication of SNc-STN dopaminergic projection in the pathophysiology of PD. Thus, bilateral infusions of D1 but not D2 receptor antagonists into the STN induced catalepsy in normal rats (Hauber, 1998) and that activation of D1 receptors resulted in orofacial dyskinesias in normal and dopamine-depleted rats (Parry et al., 1994; Mehta et al., 2000). From these studies it is suggested that dopaminergic agents acting at D1 receptors have stronger functional and behavioral effects than agents acting at D2 receptors. Several studies have shown that dopamine is reduced in the STN in experimental Parkinsonism and also in patients with PD (Pifl et al., 1990; Hornykiewicz, 1998; François et al., 2000) and such dopamine loss in the STN may contribute to increase abnormal neuronal activity. Accordingly, selective lesions of the dopaminergic fibers located in the STN, by intrasubthalamic infusion of 6-OHDA, resulted in contralateral muscle rigidity and ipsilateral turning in response to systemic administration of DL-methamphetamine (Flores et al., 1993). These motor deficits could be explained by the fact that 6-OHDA injection into the STN resulted in retrograde degeneration of dopamine cell bodies in the lateral part of the $\mathrm{SNc}$ (Ni et al., 2001a) and was at the origin of the significant increase in the percentage of STN neurons exhibiting burst pattern (Ni et al., 2001b). These results provide evidence that the degeneration of SNc-STN dopaminergic projections plays, at least in part, a role in the development of the pathological burst pattern of STN neurons and therefore to the manifestation of PD-like motor deficits. In the same 6-OHDA rat model, it has been shown that lesions of the $\mathrm{SNc}$ dopaminergic cells increased the level of dopamine D2 receptor mRNA, decreased D3 receptor mRNA levels, and did not induce significant changes in Dl receptor mRNA in the STN (Flores et al., 1999). Furthermore, several studies have shown that dopamine D5 receptors, which display a high agonist-independent constitutive activity in vitro (Tiberi and Caron, 1994; Demchyshyn et al., 2000), are located in the STN and are able to potentiate burst firing in STN neurons in in vitro rat brain slices (Baufreton et al., 2003, 2005). These authors suggested that in the parkinsonian state, the reduction of dopaminergic transmission in the STN results in a lack of activation of dopamine D2 receptors, and as D5 receptors are constitutively active even in the absenc of dopamine, they contribute to the development of burst discharges of STN neurons (Baufreton et al., 2005). This assumption has been demontsrated by our recent in vivo study, in which we have shown that local microinjection of an inverse agonist of D5 receptors, flupenthixol, reduced burst activity of STN neurons and therefore improved the motor deficits in the 6-OHDA rat model of PD (Chetrit et al., 2013). Moreover, STN dopaminergic afferents have also been suggested to play a relevant role in the expression of dyskinesias. Indeed, dopamine depletion in the STN attenuated levodopa-induced dyskinesia in rats bearing a concomitant lesion of the nigrostriatal pathway (Marin et al., 2013).

\section{CONCLUSION}

While the degeneration of the dopaminergic nigrostriatal pathway is the hallmark of $\mathrm{PD}$, there is strong evidence about the key role played by dopamine loss at extrastriatal sites, especially in the pallidal complex and the STN, in the pathophysiology of the disease. Activation of dopamine receptors in these important basal ganglia nuclei modulates their neuronal activity, and consequently participates in the beneficial effects, and may be in the adverse effects, of the classical dopaminomimetic antiparkinsonian drugs. Together, we can assume that dopamine transmission within the globus pallidus and the STN is necessary to achieve normal motor control.

\section{ACKNOWLEDGMENTS}

This study was supported by grants from the "Centre national de la Recherche Scientifique", "Université Bordeaux Segalen" and exchange grants of the "Groupement de Recherche International" (GDRI N198, CNRS and INSERM France, and CNRST Morocco), Egide-Volubilis $\mathrm{N}^{\circ}$ 20565ZM, CNRS-CNRST Convention Adivmar 22614 and NEUROMED.

\section{REFERENCES}

Abedi, P. M., Delaville, C., De Deurwaerdere, P., Benjelloun, W., and Benazzouz, A. (2013). Intrapallidal administration of 6-hydroxydopamine mimics in large part the electrophysiological and behavioral consequences of major dopamine depletion in the rat. Neuroscience 236, 289-297. doi: 10.1016/j.neuroscience. 2013.01.043

Agid, Y., and Blin, J. (1987). Nerve cell death in degenerative diseases of the central nervous system: clinical aspects. Ciba Found. Symp. 126, 3-29. doi: 10. 1002/9780470513422.ch2

Albin, R. L., Young, A. B., and Penney, J. B. (1989). The functional anatomy of basal ganglia disorders. Trends Neurosci. 12, 366-375. doi: 10.1016/01662236(89)90074-X

Alexander, G. E., and Crutcher, M. D. (1990). Functional architecture of basal ganglia circuits: neural substrates of parallel processing. Trends Neurosci. 13, 266-271. doi: 10.1016/0166-2236(90)90107-1

Anaya-Martinez, V., Martinez-Marcos, A., Martinez-Fong, D., Aceves, J., and Erlij, D. (2006). Substantia nigra compacta neurons that innervate the reticular thalamic nucleus in the rat also project to striatum or globus pallidus: implications for abnormal motor behavior. Neuroscience 143, 477-486. doi: 10.1016/j. neuroscience.2006.08.033

Baufreton, J., Garret, M., Rivera, A., De La Calle, A., Gonon, F., Dufy, B., et al. (2003). D5 (not D1) dopamine receptors potentiate burst-firing in neurons of the subthalamic nucleus by modulating an L-type calcium conductance. $J$. Neurosci. 23, 816-825.

Baufreton, J., Zhu, Z. T., Garret, M., Bioulac, B., Johnson, S. W., and Taupignon, A. I. (2005). Dopamine receptors set the pattern of activity generated in subthalamic neurons. FASEB J. 19, 1771-1777. doi: 10.1096/fj.04-3401hyp

Benazzouz, A., Breit, S., Koudsie, A., Pollak, P., Krack, P., and Benabid, A. L. (2002). Intraoperative microrecordings of the subthalamic nucleus in Parkinson's disease. Mov. Disord. 17(Suppl. 3), S145-S149. doi: 10.1002/mds.10156

Benazzouz, A., Gross, C., Feger, J., Boraud, T., and Bioulac, B. (1993). Reversal of rigidity and improvement in motor performance by subthalamic highfrequency stimulation in MPTP-treated monkeys. Eur. J. Neurosci. 5, 382-389. doi: 10.1111/j.1460-9568.1993.tb00505.x

Bergman, H., Wichmann, T., and Delong, M. R. (1990). Reversal of experimental parkinsonism by lesions of the subthalamic nucleus. Science 249, 1436-1438. doi: $10.1126 /$ science. 2402638 
Bergman, H., Wichmann, T., Karmon, B., and Delong, M. R. (1994). The primate subthalamic nucleus. II. Neuronal activity in the MPTP model of parkinsonism. J. Neurophysiol. 72, 507-520.

Bézard, E., Ferry, S., Mach, U., Stark, H., Leriche, L., Boraud, T., et al. (2003). Attenuation of levodopa-induced dyskinesia by normalizing dopamine D3 receptor function. Nat. Med. 9, 762-767. doi: 10.1038/nm875

Bokobza, B., Ruberg, M., Scatton, B., Javoy-Agid, F., and Agid, Y. (1984). $[3 \mathrm{H}]$ spiperone binding, dopamine and HVA concentrations in Parkinson's disease and supranuclear palsy. Eur. J. Pharmacol. 99, 167-175. doi: 10.1016/00142999(84)90238-3

Boraud, T., Bezard, E., Guehl, D., Bioulac, B., and Gross, C. (1998). Effects of LDOPA on neuronal activity of the globus pallidus externalis (GPe) and globus pallidus internalis (GPi) in the MPTP-treated monkey. Brain Res. 787, 157-160. doi: 10.1016/s0006-8993(97)01563-1

Bouali-Benazzouz, R., Tai, C. H., Chetrit, J., and Benazzouz, A. (2009). Intrapallidal injection of 6-hydroxydopamine induced changes in dopamine innervation and neuronal activity of globus pallidus. Neuroscience 164, 588-596. doi: 10.1016/j. neuroscience.2009.07.034

Breit, S., Bouali-Benazzouz, R., Popa, R. C., Gasser, T., Benabid, A. L., and Benazzouz, A. (2007). Effects of 6-hydroxydopamine-induced severe or partial lesion of the nigrostriatal pathway on the neuronal activity of pallidosubthalamic network in the rat. Exp. Neurol. 205, 36-47. doi: 10.1016/j. expneurol.2006.12.016

Chetrit, J., Taupignon, A., Froux, L., Morin, S., Bouali-Benazzouz, R., Naudet, F., et al. (2013). Inhibiting subthalamic D5 receptor constitutive activity alleviates abnormal electrical activity and reverses motor impairment in a rat model of Parkinson's disease. J. Neurosci. 33, 14840-14849. doi: 10.1523/JNEUROSCI. 0453-13.2013

Cortés, R., Camps, M., Gueye, B., Probst, A., and Palacios, J. M. (1989). Dopamine receptors in human brain: autoradiographic distribution of D1 and D2 sites in Parkinson syndrome of different etiology. Brain Res. 483, 30-38. doi: 10. 1016/0006-8993(89)90031-0

Cossette, M., Levesque, M., and Parent, A. (1999). Extrastriatal dopaminergic innervation of human basal ganglia. Neurosci. Res. 34, 51-54. doi: 10. 1016/s0168-0102(99)00029-2

Debeir, T., Ginestet, L., Francois, C., Laurens, S., Martel, J. C., Chopin, P., et al. (2005). Effect of intrastriatal 6-OHDA lesion on dopaminergic innervation of the rat cortex and globus pallidus. Exp. Neurol. 193, 444-454. doi: 10.1016/j. expneurol.2005.01.007

DeLong, M. R. (1990). Primate models of movement disorders of basal ganglia origin. Trends Neurosci. 13, 281-285. doi: 10.1016/0166-2236(90)90110-v

Demchyshyn, L. L., Mcconkey, F., and Niznik, H. B. (2000). Dopamine D5 receptor agonist high affinity and constitutive activity profile conferred by carboxylterminal tail sequence. J. Biol. Chem. 275, 23446-23455. doi: 10.1074/jbc. m000157200

Flores, G., Liang, J. J., Sierra, A., Martinez-Fong, D., Quirion, R., Aceves, J., et al. (1999). Expression of dopamine receptors in the subthalamic nucleus of the rat: characterization using reverse transcriptase-polymerase chain reaction and autoradiography. Neuroscience 91, 549-556. doi: 10.1016/s0306-4522 (98)00633-2

Flores, G., Valencia, J., Rosales, M. G., Sierra, A., and Aceves, J. (1993). Appearance of EMG activity and motor asymmetry after unilateral lesions of the dopaminergic innervation to the subthalamic nucleus in the rat. Neurosci. Lett. 162, 153156. doi: 10.1016/0304-3940(93)90583-7

François, C., Savy, C., Jan, C., Tande, D., Hirsch, E. C., and Yelnik, J. (2000). Dopaminergic innervation of the subthalamic nucleus in the normal state, in MPTP-treated monkeys and in Parkinson's disease patients. J. Comp. Neurol. 425, 121-129. doi: 10.1002/1096-9861(20000911)425:1<121::aid-cne10>3.0. co; $2-\mathrm{g}$

François, C., Yelnik, J., Tande, D., Agid, Y., and Hirsch, E. C. (1999). Dopaminergic cell group A8 in the monkey: anatomical organization and projections to the striatum. J. Comp. Neurol. 414, 334-347. doi: 10.1002/(sici)10969861(19991122)414:3<334::aid-cne4>3.3.co;2-o

Fuchs, H., and Hauber, W. (2004). Dopaminergic innervation of the rat globus pallidus characterized by microdialysis and immunohistochemistry. Exp. Brain Res. 154, 66-75. doi: 10.1007/s00221-003-1638-7

Galvan, A., Floran, B., Erlij, D., and Aceves, J. (2001). Intrapallidal dopamine restores motor deficits induced by 6-hydroxydopamine in the rat. J. Neural Transm. 108, 153-166. doi: 10.1007/s007020170085
Hauber, W. (1998). Blockade of subthalamic dopamine D1 receptors elicits akinesia in rats. Neuroreport 9, 4115-4118. doi: 10.1097/00001756-199812210-00020

Hauber, W., and Lutz, S. (1999). Dopamine D1 or D2 receptor blockade in the globus pallidus produces akinesia in the rat. Behav. Brain Res. 106, 143-150. doi: 10.1016/s0166-4328(99)00102-3

Hauber, W., Lutz, S., and Munkle, M. (1998). The effects of globus pallidus lesions on dopamine-dependent motor behaviour in rats. Neuroscience 86, 147-157. doi: 10.1016/s0306-4522(98)00009-8

Hedreen, J. C. (1999). Tyrosine hydroxylase-immunoreactive elements in the human globus pallidus and subthalamic nucleus. J. Comp. Neurol. 409, 400-410. doi: 10.1002/(sici)1096-9861(19990705)409:3<400::aid-cne5>3.0.co;2-4

Hornykiewicz, O. (1998). Biochemical aspects of Parkinson's disease. Neurology 51, S2-S9. doi: 10.1212/WNL.51.2_Suppl_2.S2

Hurley, M. J., Mash, D. C., and Jenner, P. (2001). Dopamine D(1) receptor expression in human basal ganglia and changes in Parkinson's disease. Brain Res. Mol. Brain Res. 87, 271-279. doi: 10.1016/s0169-328x(01)00022-5

Hutchison, W. D., Allan, R. J., Opitz, H., Levy, R., Dostrovsky, J. O., Lang, A. E., et al. (1998). Neurophysiological identification of the subthalamic nucleus in surgery for Parkinson's disease. Ann. Neurol. 44, 622-628. doi: 10.1002/ana. 410440407

Jan, C., Francois, C., Tande, D., Yelnik, J., Tremblay, L., Agid, Y., et al. (2000). Dopaminergic innervation of the pallidum in the normal state, in MPTP-treated monkeys and in parkinsonian patients. Eur. J. Neurosci. 12, 4525-4535. doi: 10. 1111/j.1460-9568.2000.01351.x

Kebabian, J. W., and Calne, D. B. (1979). Multiple receptors for dopamine. Nature 277, 93-96. doi: 10.1038/277093a0

Krack, P., Batir, A., Van Blercom, N., Chabardes, S., Fraix, V., Ardouin, C., et al. (2003). Five-year follow-up of bilateral stimulation of the subthalamic nucleus in advanced Parkinson's disease. N. Engl. J. Med. 349, 1925-1934. doi: 10. 1056/nejmoa035275

Lavoie, B., Smith, Y., and Parent, A. (1989). Dopaminergic innervation of the basal ganglia in the squirrel monkey as revealed by tyrosine hydroxylase immunohistochemistry. J. Comp. Neurol. 289, 36-52. doi: 10.1002/cne.902890104

Limousin, P., Pollak, P., Benazzouz, A., Hoffmann, D., Le Bas, J. F., Broussolle, E., et al. (1995). Effect of parkinsonian signs and symptoms of bilateral subthalamic nucleus stimulation. Lancet 345, 91-95. doi: 10.1016/s0140-6736(95) 90062-4

Lindvall, O., and Bjorklund, A. (1979). Dopaminergic innervation of the globus pallidus by collaterals from the nigrostriatal pathway. Brain Res. 172, 169-173. doi: 10.1016/0006-8993(79)90907-7

Magill, P. J., Bolam, J. P., and Bevan, M. D. (2001). Dopamine regulates the impact of the cerebral cortex on the subthalamic nucleus-globus pallidus network. Neuroscience 106, 313-330. doi: 10.1016/s0306-4522(01)00281-0

Marin, C., Bonastre, M., Mengod, G., Cortes, R., Rodriguez-Oroz, M. C., and Obeso, J. A. (2013). Subthalamic 6-OHDA-induced lesion attenuates levodopainduced dyskinesias in the rat model of Parkinson's disease. Exp. Neurol. 250, 304-312. doi: 10.1016/j.expneurol.2013.10.006

Mehta, A., Thermos, K., and Chesselet, M. F. (2000). Increased behavioral response to dopaminergic stimulation of the subthalamic nucleus after nigrostriatal lesions. Synapse 37, 298-307. doi: 10.1002/1098-2396(20000915)37:4<298::aidsyn7>3.0.co;2-a

Moore, R. Y., Whone, A. L., and Brooks, D. J. (2008). Extrastriatal monoamine neuron function in Parkinson's disease: an 18F-dopa PET study. Neurobiol. Dis. 29, 381-390. doi: 10.1016/j.nbd.2007.09.004

Ni, Z., Bouali-Benazzouz, R., Gao, D., Benabid, A. L., and Benazzouz, A. (2000). Changes in the firing pattern of globus pallidus neurons after the degeneration of nigrostriatal pathway are mediated by the subthalamic nucleus in the rat. Eur. J. Neurosci. 12, 4338-4344. doi: 10.1111/j.1460-9568.2000.01346.x

Ni, Z., Bouali-Benazzouz, R., Gao, D., Benabid, A. L., and Benazzouz, A. (2001a). Intrasubthalamic injection of 6-hydroxydopamine induces changes in the firing rate and pattern of subthalamic nucleus neurons in the rat. Synapse 40, 145-153. doi: 10.1002/syn.1036

Ni, Z. G., Bouali-Benazzouz, R., Gao, D. M., Benabid, A. L., and Benazzouz, A. (2001b). Time-course of changes in firing rates and firing patterns of subthalamic nucleus neuronal activity after 6-OHDA-induced dopamine depletion in rats. Brain Res. 899, 142-147. doi: 10.1016/s0006-8993(01)02219-3

Nobin, A., and Bjorklund, A. (1973). Topography of the monoamine neuron systems in the human brain as revealed in fetuses. Acta Physiol. Scand. Suppl. $388,1-40$. 
Parent, A., Lavoie, B., Smith, Y., and Bedard, P. (1990). The dopaminergic nigropallidal projection in primates: distinct cellular origin and relative sparing in MPTPtreated monkeys. Adv. Neurol. 53, 111-116.

Parent, A., and Smith, Y. (1987). Differential dopaminergic innervation of the two pallidal segments in the squirrel monkey (Saimiri sciureus). Brain Res. 426, 397400. doi: 10.1016/0006-8993(87)90896-1

Parent, A., Smith, Y., Filion, M., and Dumas, J. (1989). Distinct afferents to internal and external pallidal segments in the squirrel monkey. Neurosci. Lett. 96, 140 144. doi: 10.1016/0304-3940(89)90047-5

Parry, T. J., Eberle-Wang, K., Lucki, I., and Chesselet, M. F. (1994). Dopaminergic stimulation of subthalamic nucleus elicits oral dyskinesia in rats. Exp. Neurol. 128, 181-190. doi: 10.1006/exnr.1994.1126

Pavese, N., Rivero-Bosch, M., Lewis, S. J., Whone, A. L., and Brooks, D. J. (2011). Progression of monoaminergic dysfunction in Parkinson's disease: a longitudinal 18F-dopa PET study. Neuroimage 56, 1463-1468. doi: 10.1016/j.neuroimage. 2011.03.012

Pifl, C., Bertel, O., Schingnitz, G., and Hornykiewicz, O. (1990). Extrastriatal dopamine in symptomatic and asymptomatic rhesus monkeys treated with 1methyl-4-phenyl-1,2,3,6-tetrahydropyridine (MPTP). Neurochem. Int. 17, 263 270. doi: 10.1016/0197-0186(90)90148-m

Pifl, C., Reither, H., and Hornykiewicz, O. (1991). Lower efficacy of the dopamine D1 agonist, SKF 38393, to stimulate adenylyl cyclase activity in primate than in rodent striatum. Eur. J. Pharmacol. 202, 273-276. doi: 10.1016/00142999(91)90304-9

Rajput, A. H., Sitte, H. H., Rajput, A., Fenton, M. E., Pifl, C., and Hornykiewicz, O. (2008). Globus pallidus dopamine and Parkinson motor subtypes: clinical and brain biochemical correlation. Neurology 70, 1403-1410. doi: 10.1212/01.wnl. $0000285082.18969 .3 \mathrm{a}$

Rakshi, J. S., Uema, T., Ito, K., Bailey, D. L., Morrish, P. K., Ashburner, J., et al. (1999). Frontal, midbrain and striatal dopaminergic function in early and advanced Parkinson's disease A 3D [(18)F]dopa-PET study. Brain 122(Pt. 9), 1637-1650. doi: 10.1093/brain/122.9.1637

Rinne, J. O., Rinne, J. K., Laakso, K., Lonnberg, P., and Rinne, U. K. (1985). Dopamine D-1 receptors in the parkinsonian brain. Brain Res. 359, 306-310. doi: 10.1016/0006-8993(85)91441-6

Rivlin-Etzion, M., Elias, S., Heimer, G., and Bergman, H. (2010). Computational physiology of the basal ganglia in Parkinson's disease. Prog. Brain Res. 183, 259 273. doi: 10.1016/s0079-6123(10)83013-4

Rommelfanger, K. S., and Wichmann, T. (2010). Extrastriatal dopaminergic circuits of the Basal Ganglia. Front. Neuroanat. 4:139. doi: 10.3389/fnana.2010.00139

Ryoo, H. L., Pierrotti, D., and Joyce, J. N. (1998). Dopamine D3 receptor is decreased and D2 receptor is elevated in the striatum of Parkinson's disease. Mov. Disord. 13, 788-797. doi: 10.1002/mds.870130506
Sañudo-Peña, M. C., and Walker, J. M. (1998). Effects of intrapallidal cannabinoids on rotational behavior in rats: interactions with the dopaminergic system. Synapse 28, 27-32. doi: 10.1002/(sici)1098-2396(199801)28:1<27::aid-syn4>3. 3.co; $2-8$

Smith, Y., and Villalba, R. (2008). Striatal and extrastriatal dopamine in the basal ganglia: an overview of its anatomical organization in normal and Parkinsonian brains. Mov. Disord. 23(Suppl. 3), S534-S547. doi: 10.1002/mds. 22027

Surmeier, D. J., Ding, J., Day, M., Wang, Z., and Shen, W. (2007). D1 and D2 dopamine-receptor modulation of striatal glutamatergic signaling in striatal medium spiny neurons. Trends Neurosci. 30, 228-235. doi: 10.1016/j.tins.2007. 03.008

Tiberi, M., and Caron, M. G. (1994). High agonist-independent activity is a distinguishing feature of the dopamine D1B receptor subtype. J. Biol. Chem. 269, 27925-27931.

Whone, A. L., Moore, R. Y., Piccini, P. P., and Brooks, D. J. (2003). Plasticity of the nigropallidal pathway in Parkinson's disease. Ann. Neurol. 53, 206-213. doi: 10. 1002/ana.10427

Wichmann, T., Bergman, H., and Delong, M. R. (1994). The primate subthalamic nucleus. III. Changes in motor behavior and neuronal activity in the internal pallidum induced by subthalamic inactivation in the MPTP model of parkinsonism. J. Neurophysiol. 72, 521-530.

Wilson, C. J., and Bevan, M. D. (2011). Intrinsic dynamics and synaptic inputs control the activity patterns of subthalamic nucleus neurons in health and in Parkinson's disease. Neuroscience 198, 54-68. doi: 10.1016/j.neuroscience.2011. 06.049

Conflict of Interest Statement: The authors declare that the research was conducted in the absence of any commercial or financial relationships that could be construed as a potential conflict of interest.

Received: 11 April 2014; accepted: 23 April 2014 ; published online: 13 May 2014. Citation: Benazzouz A, Mamad O, Abedi P, Bouali-Benazzouz R and Chetrit J (2014) Involvement of dopamine loss in extrastriatal basal ganglia nuclei in the pathophysiology of Parkinson's disease. Front. Aging Neurosci. 6:87. doi: 10.3389/fnagi.2014.00087 This article was submitted to the journal Frontiers in Aging Neuroscience.

Copyright (c) 2014 Benazzouz, Mamad, Abedi, Bouali-Benazzouz and Chetrit. This is an open-access article distributed under the terms of the Creative Commons Attribution License (CC BY). The use, distribution or reproduction in other forums is permitted, provided the original author(s) or licensor are credited and that the original publication in this journal is cited, in accordance with accepted academic practice. No use, distribution or reproduction is permitted which does not comply with these terms. 